\title{
Gypsophila paniculata root saponins as an environmentally safe treatment against two nematodes, natural vectors of grapevine fanleaf degeneration
}

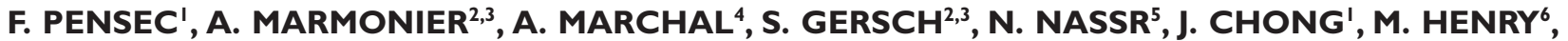 \\ G. DEMANGEAT ${ }^{2,3}$ and C. BERTSCH' \\ ' Laboratoire Vigne Biotechnologie et Environnement EA399I, Université de Haute-Alsace, 33 rue Herrlisheim, \\ F-68000 Colmar, France \\ ${ }^{2}$ UMR II3I Santé de la Vigne et Qualité du Vin, Institut National de la Recherche Agronomique, 28 rue Herrlisheim, \\ F-68000 Colmar, France \\ ${ }^{3}$ UMR II3I Santé de la Vigne et Qualité du Vin, Université de Strasbourg, 28 rue Herrlisheim, F-68000 Colmar, France \\ ${ }^{4}$ ISVV, EA 4577, Unité de recherche OENOLOGIE, Université de Bordeaux, F-33882 Villenave d'Ornon, France \\ ${ }^{5}$ RITTMO Agroenvironnement, 37 rue Herrlisheim CS800 23, F-68025 Colmar, France \\ ${ }^{6}$ Groupe S.U.C.R.E.S., UMR 7565, CNRS-Université de Lorraine BP 239, F-54506 Nancy-Vandoeuvre, France \\ Corresponding author: Dr Christophe Bertsch, email christophe.bertsch@uha.fr
}

\begin{abstract}
Background and Aims: Xiphinema index and X. diversicaudatum are nematodes that transmit the grapevine fanleaf virus and the Arabis mosaic virus, respectively. These viruses are the two agents mainly responsible for the disease that causes the most economic damage to grapevines worldwide. The infectious degeneration of grapevines affects vine performance and grape composition. The control of Xiphinema populations by soil disinfection is now impossible because of the removal from the market of the last available chemical treatments. In this study, saponins are assessed as an alternative treatment to control nematode populations.

Methods and Results: The nematicidal effect of saponins from Gypsophila paniculata roots was tested against $X$. index and $X$. diversicaudatum. In aqueous media, a concentration of $1 \mathrm{mg} / \mathrm{mL}$ was associated with a mortality of greater than $95 \%$ in both nematodes, while in rearing soil, $73 \%$ of $X$. index and $85 \%$ of $X$. diversicaudatum were killed by $150 \mu \mathrm{g}$ of saponins per gram of soil. In addition, an ecotoxicological study was undertaken on two soil bio-indicators (the mycorrhizal fungus Glomus mosseae and soil nitrification) that revealed that they were not affected by Gy. paniculata saponins at a nematicidal concentration. In the soil, investigation of the major Gy. paniculata root saponins revealed that these molecules were completely degraded in the soil within 4 days.

Conclusion: We show that Gy. paniculata saponins are an efficient and environmentally friendly treatment against two nematodes that transmit grapevine fanleaf virus.

Significance of the Study: This saponin-based alternative to chemical treatments could provide an environmentally safe and efficient solution for vine growers to use against grapevine fanleaf vector nematodes.
\end{abstract}

Keywords: environmentally friendly, grapevine fanleaf disease, Gypsophila paniculata, nematicidal, saponin

\section{Introduction}

The Grapevine fanleaf virus (GFLV) and the Arabis mosaic virus (ArMV) are two widely distributed nepoviruses responsible for a type of progressive degeneration of grapevines (AndretLink et al. 2004). The grape yield from infected vines may be reduced by up to $80 \%$, and the grape composition is affected (Andret-Link et al. 2004). The two viruses are specifically transmitted from grapevine to grapevine by the soil-borne ectoparasitic nematodes Xiphinema index and Xiphinema diversicaudatum (Hewitt et al. 1958) during the feeding process on growing roots. Both juvenile and adult nematodes can acquire and transmit viruses to healthy grapevines (Taylor and Brown 1997).

Because no natural viral resistance has been identified among Vitis species, strategies to control fanleaf diseases have focused on nematodes (Esmenjaud and Bouquet 2009). The main strategies are the direct control of the nematode population by cultural practices and by soil disinfection (Raski 1983, Taylor and Brown 1997). Hence, chemical treatments based on active substances, such as methyl bromide, fenamiphos (Nemacur, Bayer CropScience, Monheim, Germany), aldicarb (Temik 10G, Bayer Cropscience) or 1,3-dichloropropene (Telone 2000, Dow AgroScience S.A.S., Indianapolis, IN, USA), have been developed to eradicate nematodes from vineyards, but these molecules are often of limited efficiency and have acute toxicity for the environment and the user. Therefore, their use has been prohibited in several countries (Abawi and Widmer 2000) and more recently in Europe (European Commission 2007). Knowing the limited efficiency of the nematicides and because of their progressive withdrawal from the market, 
alternatives to chemical treatments have been developed, such as $X$. index tolerant rootstocks (Esmenjaud and Bouquet 2009). Transgenic rootstocks expressing sequences from the coat protein gene of GFLV (GFLV CP) have also been produced and challenged with GFLV in naturally infected vineyards or by grafting in controlled conditions (Vigne et al. 2004, Gambino et al. 2010). In a 3-year field trial, a few lines of GFLV CP transgenic rootstocks were shown to be resistant to GFLV, suggesting that transgenic grapevines may be a promising approach for the control of GFLV (Vigne et al. 2004). Jelly et al. (2012) developed artificial microRNAs targeting the CP gene of GFLV. They were tested in grapevine somatic embryos and could assist the engineering of GFLV-resistant grapes in the future. Genetic approaches, however, are still under evaluation.

Because no sustainable solutions are available today and in spite of prophylactic approaches, the only efficient strategy to eradicate the disease remains a prolonged fallow of ten years, which is economically unacceptable in most vineyards (Demangeat et al. 2005). Therefore, efforts should be made to develop new approaches for the control of nematode populations.

Plants are characterised by their ability to synthesise several various secondary metabolites, such as cyanogenic glycosides, alkaloids, fatty acids, phenolics, steroids or triterpenoids (including saponins), which have been reported to have a nematicidal activity (Chitwood 2002). Saponins are characterised by their structure, containing a triterpene or steroid aglycone, and one or more sugar chains (Hostettmann and Martson 1995), and are found as preformed compounds in roots, shoots or leaves (Goodwin and Pollock 1954, VanEtten et al. 1994). They are produced by at least 100 plant families, and their structure and activity are variable among and within species (Hostettmann and Martson 1995). Saponins are known to act as pathogen inhibitors because of their ability to complex with sterols in the plasma membrane (Bangham et al. 1962, Armah et al. 1999, Melzig et al. 2001). In planta, they act as a first barrier against a wide range of potential aerial and soil pathogens (Kreuger and Potter 1994, Osbourn et al. 1994, Papadopoulou et al. 1999, Trojanowska et al. 2001). Saponins have been described over the years as potent molecules with fungicidal and bactericidal effects, and with toxic activity to cold-blooded animals (Francis et al. 2002, Güçlü-Ustündağ and Mazza 2007). It is noteworthy that these effects depend on the plant species, the genetic origin and the part of the plant from which the saponins have been extracted. Many studies have measured the effect of saponins on human health because these molecules are used as adjuvants in vaccines or to treat infections (Güçlü-Ustündağ and Mazza 2007); their agronomic interest has recently been studied. Some extracts of saponins from Quillaja saponaria or Medicago spp. have been shown to exhibit toxic properties against Xiphinema index (San Martin and Magunacelaya 2005, Argentieri et al. 2008, Fischer et al. 2011). These studies point to a possible use of saponins to control nematodes, but in most of the studies, the nematodes were directly in contact with a saponins solution instead of a soil sample.

Gypsophila paniculata is a dicotyledonous, herbaceous perennial that originates from Eurasia and is grown from seeds (Darwent and Coupland 1966). It produces a large amount of saponins, representing up to $10 \%$ of the root dry mass, which are easily extractable (Henry et al. 1989). This study was designed to determine the efficiency of saponins from $G y$. paniculata roots in killing $X$. index and $X$. diversicaudatum, two nematodes that transmit GFLV and ArMV, respectively. The impact of saponins on nematode survival was measured first in an aqueous medium with isolated nematodes and then in nematode culture-soil supplemented with water-solubilised saponins. In addition, ecotoxicological tests based on two soil bio-indicators have been developed to determine if the use of a saponins-based treatment is harmful to the soil ecosystem and the environment. The degradation of the main Gy. paniculata saponins was also followed in soil.

\section{Materials and methods}

\section{Plant material}

Gypsophila paniculata plants cultivated for horticulture were harvested in southern France. The roots were air-dried at room temperature. Fig plants (Ficus carica L.) and raspberry plants (Rubus idaeus L.) were produced from green cuttings in a climate chamber in a rockwool substrate (16-h daily illumination, with the light gradually increasing from 1200 to 3500 lux over 30 days at $26^{\circ} \mathrm{C}$ ). The rooted green cuttings were then acclimatised in a greenhouse in sandy soil before using within the nematode culture.

\section{Extraction of saponins}

Dried roots were ground in a Waring blender. The powder was submitted to a solid-liquid extraction with $10 \% \mathrm{w} / \mathrm{w}$ aq. ethanol ( $10 \mathrm{~L}$ for $1 \mathrm{~kg}$ of dry matter) by orbital mixing in a 20 -L flask for $24 \mathrm{~h}$ each time at $25^{\circ} \mathrm{C}$ on a gyratory shaker. The ethanol combined extracts were concentrated under reduced pressure and lyophilised.

\section{Xiphinema index and X. diversicaudatum culture}

An aviruliferous population of $X$. Index and of $X$. diversicaudatum was reared on fig plants and on raspberry plants, respectively. The culture of both nematodes species was kept in 10-L containers filled with an artificial substrate composed of loess and sand $(1 / 3: 2 / 3$, mass : mass) in a greenhouse under controlled temperature $\left(20-25^{\circ} \mathrm{C}\right)$ and light $(16 \mathrm{~h}$ photoperiod) conditions.

\section{Effect of saponins on nematodes in aqueous medium}

Adult nematodes were isolated from the rearing soil by sieving, as described by Flegg (1967). Soil samples up to $250 \mathrm{~g}$ were filtered with sieves of different mesh using tap water. Xiphinema nematodes were identified and numbered under a binocular microscope. Lots of 30 isolated nematodes, in triplicate, were incubated in the dark at room temperature in plastic wells filled with $2 \mathrm{~mL}$ of saponins solubilised in distilled water at various concentrations. The effect of saponins on viability was monitored after 1, 2 and 3 days.

\section{Effect of saponins on nematodes in soil}

Soil samples $(40 \mathrm{~g})$ collected from the nematode culture were supplemented with $3 \mathrm{~mL}$ solution of saponins at several concentrations. Each soil sample was carefully homogenised, stored in Petri dishes and incubated under a controlled temperature $\left(20^{\circ} \mathrm{C}\right)$ in the dark. The soil samples were analysed after 6 hours, or $1,2,3,4$ or 7 days after treatment. All nematodes were extracted from each sample as described earlier and numbered within lots of 50 dead and alive nematodes. The experiments were performed in triplicate.

\section{Impact on Glomus mosseae germination}

Spores of Glomus mosseae purchased commercially (Biorhize, Dijon, France) were placed between two nitrocellulose membrane filters to form a sandwich. Each sandwich was put in a 
Petri dish between two layers of sand or a mixture of sand with different saponins concentrations. The sand was humidified to $75 \%$ of the water-holding capacity with distilled water or a solution of saponins. For each concentration, 30 spores were added between the two nitrocellulose membranes, and four replicates were used. Each Petri dish was sealed and incubated for 14 days at $24^{\circ} \mathrm{C}$ in the dark. After incubation, the sandwiches were submerged in Trypan blue solution $(0.05 \%)$ for $15 \mathrm{~min}$ to visualise the hyphae germination. The sandwiches were then rinsed and dried. The number of germinated spores was counted. The germination was validated when the length of the hyphae was at least five times the length of the spore.

\section{Impact on soil nitrification}

The potential toxicity of saponins to the soil microflora implied in nitrification was investigated with an international standard laboratory procedure (ISO 14238). Autotrophic ammoniumoxidising bacteria were exposed to a solution of saponins in a standard soil (Lufa 2.3, Lufa Speyer, Speyer, Germany) incubated in a microcosm at $20^{\circ} \mathrm{C}$ and humidified at $50 \%$ of the water-holding capacity of soil. A nitrogenous substrate $\left(\mathrm{NH}_{4}\right)_{2} \mathrm{SO}_{4}\left(100 \mathrm{mg} / \mathrm{kg}\right.$ of $\left.\mathrm{NH}_{4}^{+}\right)$was mixed thoroughly and homogeneously into the soil before incubation. Solutions of saponins at different concentrations were then added to these soil samples. The saponins-free samples served as the untreated controls. Three replicates were prepared for each treatment and at different times of incubation. To determine the impact of saponins on soil nitrification, soil samples (25 g per replicate) were analysed directly after treatment and at various times of incubation $(7,14$ or 21 days). Thus, sampling at each incubation time allowed the evaluation of the kinetics of ammonium oxidation and the production of nitrate (in mg of $\mathrm{NO}_{3}{ }^{-} / \mathrm{kg}$ of soil dry mass). Extracts of ammonium, nitrite and nitrate from the samples of soil were obtained by shaking samples with 100-mL potassium chloride solution $(1 \mathrm{~mol} / \mathrm{L} \mathrm{KCl})$ at $15 \mathrm{rpm}$ for one hour (HeidolphReax, Grosseron, Saint Herblain, France). The fine particles of soil were removed from the extracts by filtration using filter paper $(12-15 \mu \mathrm{m})$. Particle-free extracts were stored at $\left(-20^{\circ} \mathrm{C}\right)$ until analysis of $\mathrm{NH}_{4}{ }^{+}, \mathrm{NO}_{2}^{-}$and $\mathrm{NO}_{3}{ }^{-}$(Regional Research and Analyses Laboratory LDAR, Laon, France).

\section{Evolution of saponins in soil}

To understand how saponins evolve in soil, $40 \mathrm{~g}$ of the nematicidal test soil were placed in Petri dishes, treated with $3 \mathrm{~mL}$ of a saponins solution and stored at $20^{\circ} \mathrm{C}$. The samples were assayed in triplicate at zero and $6 \mathrm{~h}$, or at one, four and seven days. After the addition of $10 \mathrm{~mL}$ of ultra high quality water, the soil solution was transferred to Falcon tubes and centrifuged at $4000 \times g$ for $2 \mathrm{~min}$. The supernatant was collected and filtered with $0.45-\mu \mathrm{m}$ filter. Each solution was then analysed by liquid chromatography-Fourier transform mass spectrometry (LC-FTMS).

\section{Analysis of soil extracts treated with saponins by LC-FTMS}

The LC-FTMS platform consisted of an HTC PAL autosampler (CTC Analytics AG, Zwingen, Switzerland), an Accela ultra high performance liquid chromatography (U-HPLC) system with quaternary pumps and an Exactive benchtop Orbitrap mass spectrometer equipped with a heated electrospray ionisation (HESI) probe (both from Thermo Fisher Scientific, Bremen, Germany). For liquid chromatography separation, a $\mathrm{Cl} 8$ column was used as the stationary phase (Hypersil Gold $2.1 \mathrm{~mm} \times 100 \mathrm{~mm}, 1.9 \mu \mathrm{m}$ particle size, Thermo Fisher Scientific). The mobile phases were (i) water and (ii) acetonitrile. The flow rate was $600 \mu \mathrm{L} / \mathrm{min}$ and eluent B varied as follows: $0 \mathrm{~min}$, $14 \%$; $0.5 \mathrm{~min}, 14 \%$; $6 \mathrm{~min}, 60 \%$; $6.1 \mathrm{~min}, 95 \%$; $8.5 \mathrm{~min}, 95 \%$; $8.6 \mathrm{~min}, 14 \%$; and $10 \mathrm{~min}, 14 \%$. The injection volume was $10 \mu \mathrm{L}$. Mass acquisitions were carried in negative Fourier transform mass spectrometry (FTMS) ionisation mode at a unit resolution of $25000(\mathrm{~m} / \Delta m$, fwhm at $m / z 200 \mathrm{Th})$. The sheath and auxiliary gas flows (both nitrogen) were optimised at 75 and 15 arbitrary units, respectively. The HESI probe and capillary temperatures were 320 and $350^{\circ} \mathrm{C}$, respectively. The electrospray voltage was set to $3.5 \mathrm{kV}$, the capillary voltage to $95 \mathrm{~V}$, the tube lens voltage offset to $190 \mathrm{~V}$ and the skimmer voltage to $46 \mathrm{~V}$. Mass spectra were recorded from 400 to 1900 Th, with an automatic gain control value of $10^{6}$. External mass calibration using Pierce ESI Negative Ion Calibration solution (Thermo Fisher Scientific) was performed before each analytical series. All data were processed using the Qualbrowser application of Xcalibur version 2.1 (Thermo Fisher Scientific), and the peak areas were determined by automatic integration.

\section{Statistical analysis}

The data collected were subjected to a one-way analysis of variance (ANOVA). The treatment means were compared using Fisher's least significant difference pairwise procedure at $P<0.05$.

\section{Results}

Saponins from Gy. paniculata roots affect the viability of $\mathrm{X}$. index and $\mathrm{X}$. diversicaudatum in liquid medium To evaluate the effect of saponins extracted from Gy. paniculata on the viability of nematodes, batches of $30 \mathrm{X}$. index or 30 $X$. diversicaudatum were incubated in an aqueous solution of saponins at $0,100,200,300,400,500$ or $1000 \mu \mathrm{g} / \mathrm{mL}$. The impact of the saponins treatment was visually estimated by counting the nematodes, both live and dead. Dead nematodes are inactive and typically comma-shaped (Taylor and Brown 1997), whereas unaffected nematodes are active and adopt flexible shapes. After 3 days of incubation (Figure 1), a concentration of saponins less than $200 \mu \mathrm{g} / \mathrm{mL}$ did not affect the viability of nematodes, whereas a concentration from 200 to

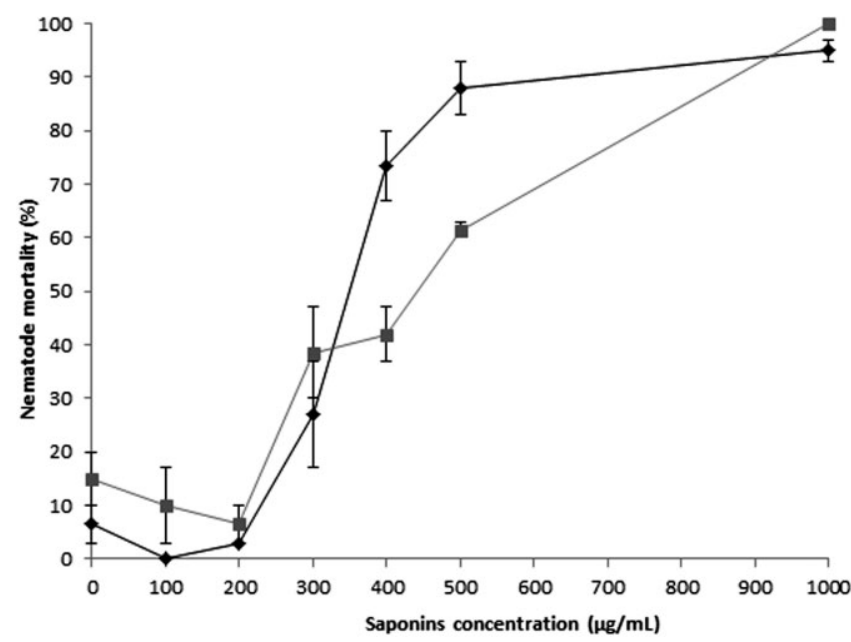

Figure 1. Impact of saponins on the mortality rate of nematodes in aqueous media. Free isolated Xiphinema diversicaudatum $(\bullet)$ or Xiphinema index $(\square)$ were incubated in the presence of an increasing concentration of saponins. After $72 \mathrm{~h}$, live and dead nematodes were counted and compared with the viability of nematodes incubated in water. 
$500 \mu \mathrm{g} / \mathrm{mL}$ exponentially increased nematode mortality, respectively, from 6 to $61 \%$ for $X$. index and from 3 to $88 \%$ for $X$. diversicaudatum. Above $500 \mu \mathrm{g} / \mathrm{mL}$, the $X$.diversicaudatum mortality rate reached a plateau and moved slowly to $100 \%$. The exponential progression of the mortality rate for $X$. index was less visible, but the evolution was similar and reached $100 \%$ at $1000 \mu \mathrm{g} / \mathrm{mL}$. The concentration required to kill $50 \%$ of the nematodes, lethal dose $50 \%$ (LD50), was $350 \mu \mathrm{g} / \mathrm{mL}$ for $X$. diversicaudatum and $450 \mu \mathrm{g} / \mathrm{mL}$ for $X$. index. These results indicate that an extract of Gy. paniculata saponins exhibited a lethal effect against the two virus vector species in aqueous media.

\section{Saponins extracted from $\mathrm{Gy}$. paniculata reduce the viability of nematodes in soil}

Soil samples harbouring $X$. index or $X$. diversicaudatum were supplemented with an extract of water-solubilised saponins to achieve a concentration range of $75,150,225,300$ or $375 \mu \mathrm{g} / \mathrm{g}$ of soil. After incubation at $20^{\circ} \mathrm{C}$ from $6 \mathrm{~h}$ to 7 days, the nematodes were isolated from the soil samples. The viability of nematodes in soil was measured as in aqueous media. As soon as $6 \mathrm{~h}$ after treatment, soil samples with a saponins concentration equal to or higher than $150 \mu \mathrm{g} / \mathrm{g}$ of soil showed a nematicidal effect in a concentration-dependent manner (Figure 2). A saponins concentration of $375 \mu \mathrm{g} / \mathrm{g}$ of soil was associated with a mortality rate of $65 \%$ for $X$. index and $60 \%$ for $X$. diversicaudatum. For both nematodes, the three highest concentrations $(225,300$ and $375 \mu \mathrm{g} / \mathrm{g})$ were associated with the highest mortality rate only 1 day after treatment. Seven days after treatment, the mortality rates caused by 225, 300 and $375 \mu \mathrm{g} / \mathrm{g}$ were, respectively, 93, 99 and $100 \%$ for $X$. index and 94, 97 and $97 \%$ for $X$. diversicaudatum. The effect of the two lowest concentrations also reached a maximum 1 day after treatment in $X$. index. No direct effect was observed on $X$. diversicaudatum; the mortality rate remained constant after 3 days with a treatment of $75 \mu \mathrm{g} / \mathrm{g}$ and after 4 days with a treatment of $150 \mu \mathrm{g} / \mathrm{g}$. Seven days after treatment, saponins at 75 and $150 \mu \mathrm{g} / \mathrm{g}$ caused the death of 22 and $73 \%$ of the $X$. index and 60 and $85 \%$ of the $X$. diversicaudatum populations, respectively (Figure 2). The LD50, 7 days after treatment, was $55 \mu \mathrm{g} / \mathrm{g}$ of soil for $X$. diversicaudatum and $120 \mu \mathrm{g} / \mathrm{g}$ for $X$. index. These results suggest that $X$. diversicaudatum is more sensitive to the lowest concentration than $X$. index. This sensitivity was also observed in the liquid media. It was observed that at 75 and $150 \mu \mathrm{g} / \mathrm{g}, X$. diversicaudatum was immobile at first glance and moved slowly only after being touched. Such concentrations may have affected the nematodes, which died a few days later. For both nematodes, the optimum treatment was $150 \mu \mathrm{g} / \mathrm{g}$, which killed $73 \%$ of the $X$. index and $85 \%$ of the $X$. diversicaudatum within seven days. Such a concentration could be used to control nematode populations.

\section{Saponins from Gy. paniculata have a low impact on Glomus} mosseae germination

This direct acute bioassay allows the evaluation of the potential effect of saponins on beneficial soil microorganisms that are important for vine growth and phosphorus nutrition. Spore germination of the mycorrhizal fungus Gl. mosseae was studied using an international standard (ISO 10382). Saponins were tested at a concentration of $0,100,200$ or $300 \mu \mathrm{g} / \mathrm{g}$ dry mass of substrate. The germination rate of Gl.mosseae spores in the untreated control was $90 \%$ after 14 days of incubation in a sand substrate (Figure 3). Even if spore germination tended to decline with increasing saponins concentration, Gl. mosseae ger- (a)
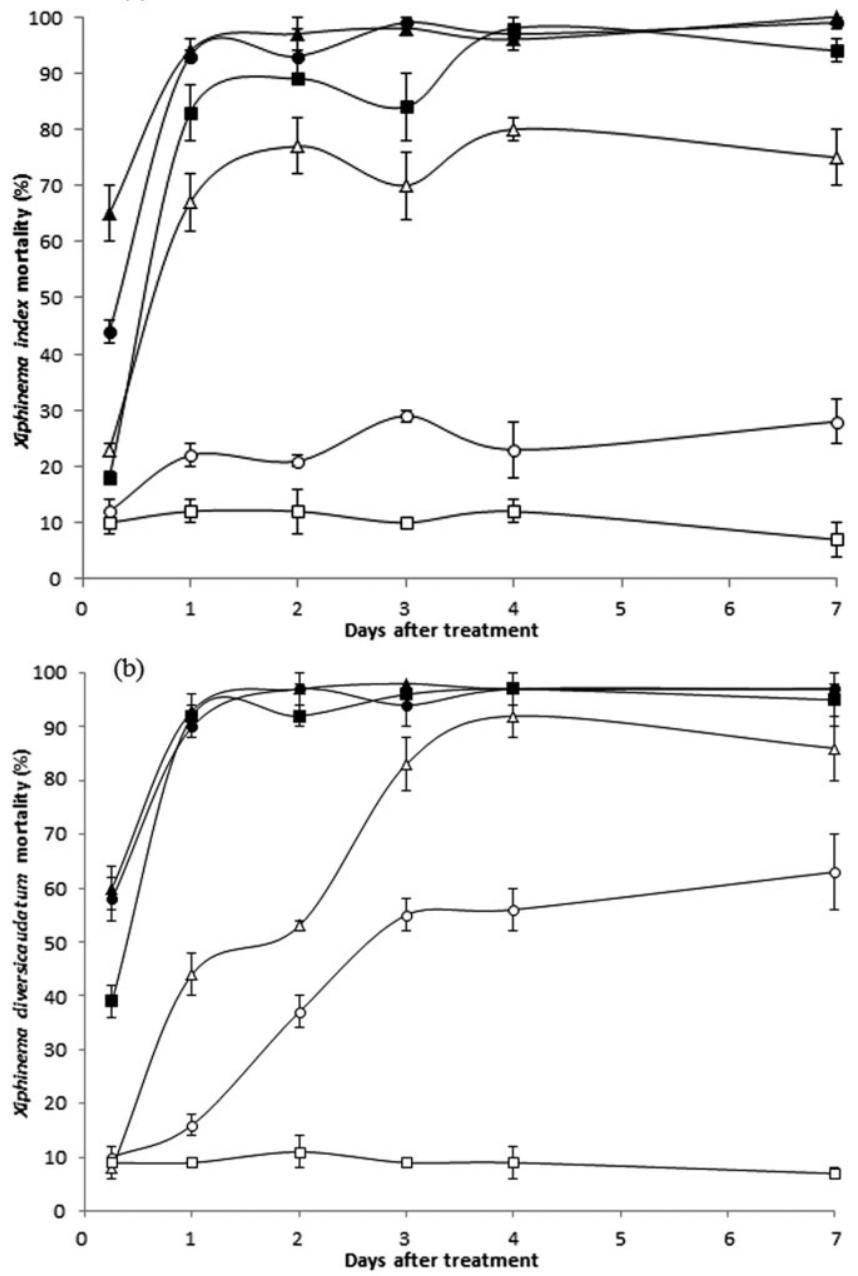

Figure 2. Impact of soil supplemented with saponins at a concentration of: $0(\square), 75(\bigcirc), 150(\triangle), 225(\boldsymbol{\square}), 300(\mathbf{\bullet})$ and $375(\mathbf{\Delta})$ $\mu \mathrm{g} / \mathrm{g}$ on the mortality rate over seven days of (a) Xiphinema index and (b) X. diversicaudatum.

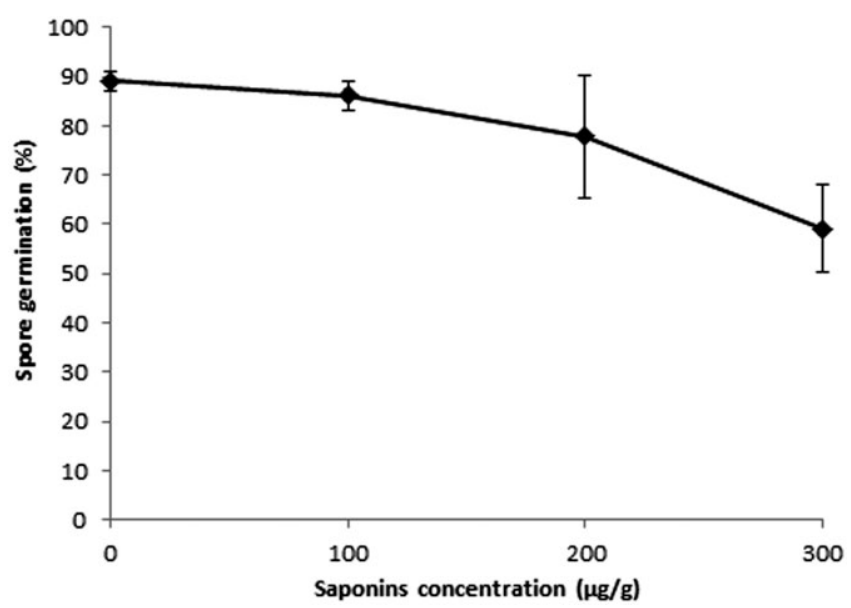

Figure 3. Germination rate of Glomus mosseae spores after 14 days contact with between 0 and $300 \mu \mathrm{g} / \mathrm{g}$ saponins.

mination in samples treated with 100 and $200 \mu \mathrm{g} / \mathrm{g}$ of soil was not significantly different from that of the control (Figure 3). The $300 \mu \mathrm{g} / \mathrm{g}$ concentration inhibited germination by $33 \%$; however, this maximal dose to evaluate the potential toxicity of 
saponins on mycorrhizal fungi was higher than the $150 \mu \mathrm{g} / \mathrm{g}$ optimum nematicidal concentration. Moreover, Gl. mosseae germination was undertaken in sand, which means that the saponins may have been less adsorbed than in the nematode rearing soil; hence, the antifungal effect may have been maximised. Furthermore, all spores were intact, so the inhibition was not due to osmoticity. Most spores counted as nongerminated spores were in fact germinated spores with small hyphae (length inferior to five times the length of the spore). Thus, saponins may not prevent the germination of Gl. mosseae spores but instead inhibit hyphae growth.

\section{Soil nitrification is not affected by saponins extracts}

Ammonium oxidation, the first step in autotrophic nitrification in soil, is used to assess the potential activity of microbial nitrifying populations. These bacteria are able to transform ammonium transitorily into nitrite and then to nitrate. To determine the effect of saponins at a concentration of $0,100,200$ or $300 \mu \mathrm{g} / \mathrm{g}$ of soil on the activity of nitrifying bacteria in soil using an international standard, the rate of nitrate formation was compared with that in the untreated control. The kinetics of $\mathrm{NH}_{4}{ }^{+}$consumption and $\mathrm{NO}_{3}{ }^{-}$production in soils mixed with saponins were similar to those observed in the control. The concentration of $\mathrm{NH}_{4}{ }^{+}$and $\mathrm{NO}_{3}{ }^{-}$in the soil crossed at approximately 12 days for each saponins concentration (Figure 4).

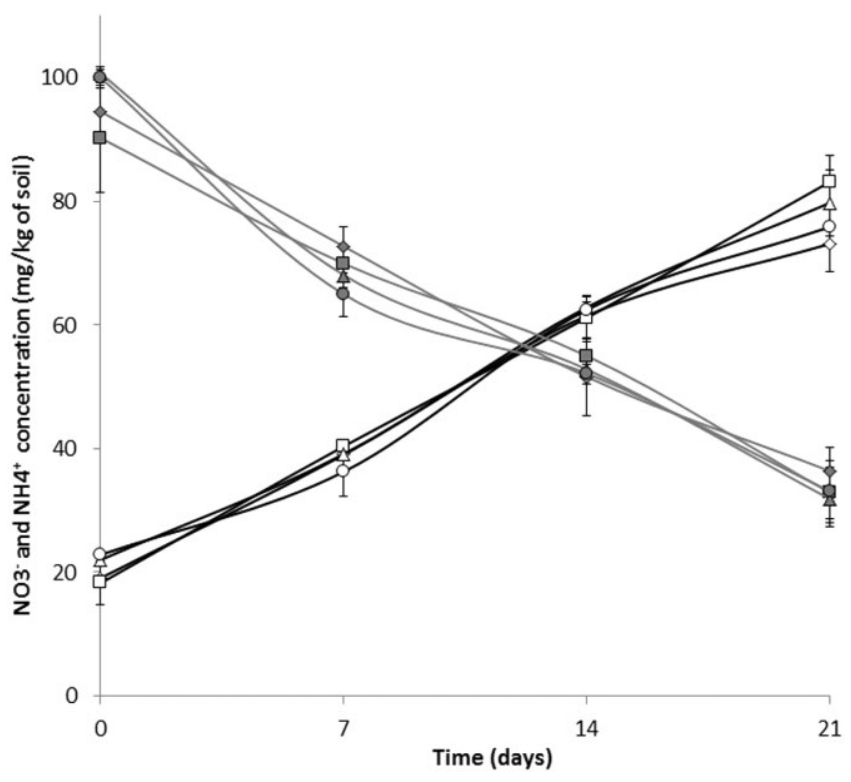

Figure 4. Impact of soil supplemented with an extract of saponins at a concentration of $0(\diamond), 100(\square), 200(\triangle)$ and $300(\bigcirc) \mu \mathrm{g} / \mathrm{g}$ on the kinetics and on the concentration of ammonium ion $(\diamond, \square, \triangle$, $\bigcirc)$ and nitrate ion $(\diamond, \square, \Delta, \bigcirc)$.
Moreover, 21 days after treatment, the amount of $\mathrm{NH}_{4}^{+}$and $\mathrm{NO}_{3}{ }^{-}$in saponins-treated soils was similar to that of the controls.

\section{Saponins are quickly degraded in soil}

Given the results obtained in soil, the degradation of a concentration of $150 \mu \mathrm{g} / \mathrm{g}$ saponins was evaluated in soil.

Preliminary LC-FTMS analysis showed that the aqueous solution of Gy. paniculata root extract contained five major saponins. Their empirical formulae were determined following the procedure described by Marchal et al. (2011) and are presented in Table 1. Because of the accuracy and stability of mass measurement concomitantly with high resolution and large dynamic range, FTMS is an efficient tool for compound quantification (Bekaert et al. 2012, Kaufmann 2012). After data acquisition in full scan mode, an extracted chromatogram was obtained for each saponin using the calculated molecular mass of the quasimolecular ion $[\mathrm{M}-\mathrm{H}]^{-}$with a mass tolerance of $5 \mathrm{ppm}$. The high specificity of FTMS provided excellent signalto-noise ratios and allowed automatic integration of the peak corresponding to the compound. The area of these peaks was related to the concentration in saponins and consequently was used to follow the evolution of saponins in soil. For each analysis, three biological replicates were injected, and all the relative standard deviations were less than $10 \%$ indicating a good repeatability for the method. The evolution of the concentration of each saponin in soil enabled the determination of its half-life, i.e. the time required for half of the molecule to either be transformed to another compound or to be leached from the sample area. Four days after treatment, none of the saponins were detected in the soil samples. Saponins S3 and S4 had the shortest half-life, 12.4 and $13.1 \mathrm{~h}$, respectively (Table 1). The half-life of S2 was $26.1 \mathrm{~h}$, and the two lowest molecular mass saponins, S1 and S5, had the longest half-life of 46.9 and $60.2 \mathrm{~h}$, respectively. These half-lives indicated that the major saponins found in Gy. paniculata root extract were quickly degraded in soil samples.

\section{Discussion}

The GFLV and the ArMV are two widely distributed nepoviruses responsible for the progressive degeneration of grapevines. Our experiments show that Gy. paniculata saponins could be an environmentally friendly and efficient treatment against the two nematode vectors of these viruses.

The results from the aqueous media showed that Gy. paniculata saponins exhibit a toxic effect on $X$. index and $X$. diversicaudatum. For $X$. index, a concentration of Gy. paniculata saponins above $500 \mu \mathrm{g} / \mathrm{mL}$ was able to kill more than $50 \%$ of the nematode population within $72 \mathrm{~h}$, and a higher concentration (up to $1000 \mu \mathrm{g} / \mathrm{mL}$ ) triggered a mortality of $100 \%$. Xiphinema diversicaudatum was sensitive to a lower concentration; the $50 \%$ mortality index was obtained with

Table 1. Characteristics of the major saponins observed in extracts of Gypsophila paniculata roots.

\begin{tabular}{lcccc}
\hline Compound $\dagger$ & Retention time (min) & m/z & Empirical formula & Half-life (h) \\
\hline S1 & 3.33 & 971.44933 & $\mathrm{C}_{47} \mathrm{H}_{72} \mathrm{O}_{21}$ & $46.9 \pm 2.0$ \\
S2 & 4.01 & 1673.70758 & $\mathrm{C}_{75} \mathrm{H}_{118} \mathrm{O}_{41}$ & $26.1 \pm 6.0$ \\
S3 & 4.22 & 1353.63323 & $\mathrm{C}_{63} \mathrm{H}_{102} \mathrm{O}_{31}$ & $12.4 \pm 0.5$ \\
S4 & 4.30 & 1221.59097 & $\mathrm{C}_{58} \mathrm{H}_{94} \mathrm{O}_{27}$ & $13.1 \pm 0.6$ \\
S5 & 4.70 & 955.45442 & $\mathrm{C}_{47} \mathrm{H}_{72} \mathrm{O}_{20}$ & $60.2 \pm 1.8$ \\
\hline
\end{tabular}

†For convenience, the saponins are designated S1-S5, in ascending order of their retention time. $\ddagger$ Monoisotopic mass of the $[\mathrm{M}-\mathrm{H}]^{-}$ion (in Th). 
$400 \mu \mathrm{g} / \mathrm{mL}$ in $72 \mathrm{~h}$. Recent studies using saponins from Medicago spp. and Q. saponaria against $X$. index described a similar nematicidal effect at $500 \mu \mathrm{g} / \mathrm{mL}$ after $48 \mathrm{~h}$ and at $300 \mu \mathrm{g} / \mathrm{mL}$ after $24 \mathrm{~h}$, respectively (Argentieri et al. 2008, Fischer et al. 2011).

Few studies have evaluated the real impact of saponin preparations on nematodes in soil samples or in fields. Our results revealed a lethal effect on both nematode species in rearing-soil. A saponins-rich extract administered at $150 \mu \mathrm{g} / \mathrm{g}$ in the soil raised the mortality of $X$. index and $X$. diversicaudatum by 73 and $85 \%$, respectively. Curves for a concentration of 75 and $150 \mu \mathrm{g} / \mathrm{g}$ reached a plateau 1 day after treatment for $X$. index and 3 days after treatment for $X$. diversicaudatum (Figure 2), indicating that saponins might degrade quickly in the soil and have no prolonged effect. This hypothesis is confirmed by our investigations because the major saponins found in our extract have a half-life ranging from 12 to $60 \mathrm{~h}$ when homogenised within the soil used to rear nematodes.

The environmental toxicity of Gy.paniculata saponins towards some bio-indicators has been evaluated in this study. The tests indicate that at suggested nematicidal concentrations, saponins extracted from Gy. paniculata roots have no effect on mycorrhizal fungal germination or on the activity of nitrifying bacteria in soil. A decrease in Gl. mosseae spore germination was only observed for a concentration of $300 \mu \mathrm{g} / \mathrm{g}$ saponins, which is twice as high as the optimal nematicidal concentration. Furthermore, a recent study showed that Chlorophytum borivilianum mycorrhization led to an increase in saponins production by this plant (Dave and Tarafdar 2011). Hence, mycorrhization and saponins are most likely not antagonistic. On the contrary, Levanon et al. (1982) suggested that nitrification is affected by an alfalfa root extract containing saponins, but this result was mostly linked to the high amount of free sugars in the root extracts that reduced the nitrification process rather than the viability of the nitrifying bacterial population.

The purpose of this study was to evaluate the action of saponins from Gy. paniculata against two nematodes and on the environment. The results show that saponins are effective against $X$. index and $X$. diversicaudatum, and are environmentally friendly towards two bio-indicators. Our experimental data indicate that $150 \mu \mathrm{g}$ of saponins/gram of soil enables the control of approximately $75 \%$ of the nematode population present in a soil sample. This concentration was chosen because it causes high nematode mortality rates and its impact on the environment is limited. This dose is equivalent to $450 \mathrm{~kg} / \mathrm{ha}$. The chemicals previously used to control nematode populations were spread at equivalent amounts: $200 \mathrm{~kg} / \mathrm{ha}$ for Temik 10G (aldicarb 10\%) and 475 L/ha for Telone 2000 (1,3dichloropropene $1100 \mathrm{~g} / \mathrm{L})$. San Martin and Magunacelaya (2005) experimented with saponins from Q. saponaria against $X$. index in vineyards in comparison with chemicals. The amount they applied was $16.5 \mathrm{~kg} / \mathrm{ha}$ of a saponins and polyphenol extract from Q. saponaria and $10 \mathrm{~L} /$ ha Nemacur (fenamiphos $400 \mathrm{~g} / \mathrm{L}$, i.e. $4 \mathrm{~kg} / \mathrm{ha}$ ). The concentration used by San Martin and Magunacelaya was lower than that used in this study, but their treatments, including the chemical treatments, were not efficient against nematodes.

The use of nematicidal chemicals has been prohibited in several countries because of their toxicity for the environment and the user. Therefore, it is also important to evaluate the toxicity of saponins towards humans and mammals. Gypsophila paniculata saponins have not been tested against mammals, but the Q. saponaria saponins LD50 for rats is $3000 \mathrm{mg} / \mathrm{kg}$ (United States Environmental Protection Agency, Office of Pesticide Programs 2009). In comparison, the LD50 of aldicarb, fenamiphos and 1,3-dichloropropene are 1, 2.4 and $250 \mathrm{mg} / \mathrm{kg}$, respectively. Thus, the toxicity of saponins towards mammals is $12-3000$ times lower than the toxicity of previously used chemicals. In addition, the major saponins from Gy. paniculata are quickly degraded in soil because their half-life is less than 3 days, whereas formerly used active substances such as aldicarb have a half-life ranging from 1.5 to 2 months depending on the soil (Jones 1987).

Saponins have already found potential application in agriculture as adjuvants (Chapagain and Wiesman 2006) and as natural pesticides (Moldstim, Pavstim, Headspu, QL AgriTM). Further experiments should be undertaken to use saponins from Gy. paniculata against pest nematodes in vineyards. Tests will be run in vineyard soils to determine the best concentration to control nematode populations and the best means of application for an environmentally friendly treatment of grapevines.

\section{Acknowledgements}

This work was made possible by the financial assistance of FranceAgrimer, CIVA and the Alsace region.

\section{References}

Abawi, G.S. and Widmer, T.L. (2000) Impact of soil health management practices on soilborne pathogens, nematodes and root diseases of vegetable crops. Applied Soil Ecology 15, 37-47.

Andret-Link, P., Laporte, C., Valat, L., Ritzenthaler, C., Demangeat, G., Vigne, E., Laval, V., Pfeiffer, P., Stussi-Garaud, C. and Fuchs, M. (2004) Grapevine fanleaf virus: still a major threat to the grapevine industry. Journal of Plant Pathology 86, 183-195.

Argentieri, M.P., D'Addabbo, T., Tava, A., Agostinelli, A., Jurzysta, M. and Avato, P. (2008) Evaluation of nematicidal properties of saponins from Medicago spp. European Journal of Plant Pathology 120, 189-197.

Armah, C.N., Mackie, A.R., Roy, C., Price, K., Osbourn, A.E., Bowyer, P. and Ladha, S. (1999) The membrane-permeabilizing effect of avenacin A-1 involves the reorganization of bilayer cholesterol. Biophysical Journal 76, 281-290.

Bangham, A.D., Horne, R.W., Glauert, A.M., Dingle, J.T. and Lucy, J.A. (1962) Action of saponin on biological cell membranes. Nature 196, 952955.

Bekaert, K.M., Vanden Bussche, J., François, S., Tuyttens, F.A.M., De Brabander, H.F., Vandendriessche, F. and Vanhaecke, L. (2012) A validated ultra-high performance liquid chromatography coupled to high resolution mass spectrometry analysis for the simultaneous quantification of the three known boar taint compounds. Journal of Chromatogratography A 1239, 49-55.

Chapagain, B.P. and Wiesman, Z. (2006) Phyto-saponins as a natural adjuvant for delivery of agromaterials through plant cuticle membranes. Journal of Agricultural and Food Chemistry 54, 6277-6285.

Chitwood, D.J. (2002) Phytochemical based strategies for nematode control. Annual Review of Phytopathology 40, 221-249.

Darwent, A.L. and Coupland, R.T. (1966) Life history of Gypsophila paniculata. Weeds 14, 313-318.

Dave, S. and Tarafdar, J.C. (2011) Stimulatory synthesis of saponin by mycorrhizal fungi in safed musli (Chlorophytum borivilianum) tubers. International Research Journal of Agricultural Science and Soil Science 1, 137-141.

Demangeat, G., Voisin, R., Minot, J.C., Bosselut, N., Fuchs, M. and Esmenjaud, D. (2005) Survival of Xiphinema index in vineyard soil and retention of Grapevine fanleaf virus over extended time in the absence of host plants. Phytopathology 95, 1151-1156.

Esmenjaud, D. and Bouquet, A. (2009) Selection and application of resistant germplasm for grapevine nematodes management. Ciancio, A. and Mukerji, K.G., eds. Integrated management of fruit crops and forest nematodes, integrated management of plant pests and diseases. Volume 4. (Springer Science: Dordrecht, the Netherlands) pp. 195-214.

European Commission (2007) Council decision of 20 September 2007 concerning the no inclusion of 1,3-dichloropropene in Annex I to Council Directive 91/414/EEC and the withdrawal of authorisations for plant protection products containing that substance (notified under document number C(2007) 4281). Official Journal of the European Union L249, $11-13$. 
Fischer, M., Pensec, F., Demangeat, G., Farine, S., Chong, J., Ramirez-Suero, M., Mazet, F. and Bertsch, C. (2011) Impact of Quillaja saponaria saponins on grapevine ecosystem organisms. Antonie van Leeuwenhoek 100, 197206.

Flegg, J.J.M. (1967) Extraction of Xiphinema and Longidorus species from soil by a modification of Cobb's decanting and sieving technique. Annals of Applied Biology 60, 429-437.

Francis, G., Kerem, Z., Makkar, H.P.S. and Becker, K. (2002) The biological action of saponins in animal systems: a review. British Journal of Nutrition 88, 587-605.

Gambino, G., Perrone, I., Carra, A., Chitarra, W., Boccacci, P., Torello Marinoni, D., Barberis, M., Maghuly, F., Laimer, M. and Gribaudo, I. (2010) Transgene silencing in grapevines transformed with GFLV resistance genes: analysis of variable expression of transgene, siRNAs production and cytosine methylation. Transgenic Research 19, 17-27.

Goodwin, R.H. and Pollock, B.M. (1954) Studies on roots. I. Properties and distribution of fluorescent constituents in Avena roots. American Journal of Botany 41, 516-520.

Güçlü-Ustündă̆, O. and Mazza, G. (2007) Saponins: properties, applications and processing. Critical Reviews in Food Science and Nutrition 47, 231258.

Henry, M., Pauthe-Dayde, D. and Rochd, M. (1989) Extraction and highperformance liquid chromatographic determination of gypsogenin 3,Oglucuronide. Journal of Chromatography A 477, 413-419.

Hewitt, W.B., Raski, D.J. and Goheen, A.C. (1958) Nematode vector of soilborne fanleaf virus of grapevines. Phytopathology 48, 586-595.

Hostettmann, K. and Martson, A. (1995) Saponins (Cambridge University Press: New York, NY, USA).

Jelly, N., Schellenbaum, P., Walter, B. and Maillot, P. (2012) Transient expression of artificial microRNAs targeting Grapevine fanleaf virus and evidence for RNA silencing in grapevine somatic embryos. Transgenic Research 21, 1319-1327.

Jones, R.L. (1987) Central California studies on the degradation and movement of aldicarb residues. Journal of Contaminant Hydrology 1, 287-298. Kaufmann, A. (2012) Chapter 4-high mass resolution versus MS/MS. Comprehensive Analytical Chemistry 58, 169-215.

Kreuger, B. and Potter, D.A. (1994) Changes in saponins and tannins in ripening holly fruits and effects of fruit consumption on nonadapted insect herbivores. American Midland Naturalist 132, 183-191.

Levanon, D., Henis, Y., Okon, Y. and Dovrat, A. (1982) Alfalfa saponins and microbial transformations of nitrogen in peat. Soil Biology and Biochemistry 14, 501-504.
Marchal, A., Waffo-Téguo, P., Génin, E., Mérillon, J.M. and Dubourdieu, D. (2011) Identification of new natural sweet compounds in wine using centrifugal partition chromatography-gustatometry and Fourier transform mass spectrometry. Analytical Chemistry 83, 9629-9637.

Melzig, M.F., Bader, G. and Loose, R. (2001) Investigations of the mechanism of membrane activity of selected triterpenoid saponins. Planta Medica 67, 43-48.

Osbourn, A.E., Clarke, B.R., Lunness, P., Scott, P.R. and Daniels, M.J. (1994) An oat species lacking avenacin is susceptible to infection by Gaeumannomyces graminis var. tritici. Physiological and Molecular Plant Pathology 45, 457-467.

Papadopoulou, K., Melton, R.E., Leggett, M., Daniels, M.J. and Osbourn, A.E. (1999) Compromised disease resistance in saponin-deficient plants. Proceedings of the National Academy of Sciences of the United States of America 96, 12923-12928.

Raski, D.J. (1983) Strategies against grapevine fanleaf virus and its nematode vector. Plant Disease 67, 335-339.

San Martin, R. and Magunacelaya, J.C. (2005) Control of plant-parasitic nematodes with extracts of Quillaja saponaria. Nematology 7, 577-585.

Taylor, C.E. and Brown, D.J.F. (1997) Nematode vectors of plant viruses (Cab International: New York).

Trojanowska, M.R., Osbourn, A.E., Daniels, M.J. and Threlfall, D.R. (2001) Investigation of avenacin-deficient mutants of Avena strigosa. Phytochemistry 56, 121-129.

United States Environmental Protection Agency, Office of Pesticide Programs (2009) Biopesticides registration action document: saponins of Quillaja saponaria.

VanEtten, H.D., Mansfield, J.W., Bailey, J.A. and Farmer, E.E. (1994) Two classes of plant antibiotics: phytoalexins versus 'phytoanticipins'. The Plant Cell 6, 1191-1192.

Vigne, E., Komar, V. and Fuchs, M. (2004) Field safety assessment of recombination in transgenic grapevines expressing the coat protein gene of Grapevine fanleaf virus. Transgenic Research 13, 165-179.

Manuscript received: 7 December 2012

Revised manuscript received: 8 February 2013

Accepted: 9 April 2013 